\title{
O SABER FILOSÓFICO PARA AQUÉM DE TEÓRICO E PRÁTICO
}

[PHILOSOPHICAL KNOWLEDGE BEYOND THEORETICAL AND PRACTICAL]

\author{
Miguel Antonio do Nascimento
}

Doutor em Filosofia pela UFRJ, Professor do Departamento de Filosofia e da Pós-graduação em Filosofia da UFPB.

(E-mail: migueln.uppb@gmail.com)

Recebido em: 29 de janeiro de 2018. Aprovado em: 31/01/2018 


\section{O saber filosófico para aquém de teórico e prático NASCIMENTO, Miguel A.}

Resumo: O presente artigo consiste em reflexão sobre o saber filosófico em face da sistematização da filosofia, decorrida depois de seus primórdios. Tendo em vista esse fato como tal, procura-se aqui tornar relevante o debate que seja capaz de reconhecer o conteúdo de filosófico subentendido no percurso histórico da filosofia. Considera-se que isso traz consigo uma dificuldade peculiar para se estabelecer a diferença principal entre a filosofia e as demais formas de conhecimento. Considera-se também que o tratamento acadêmico dado ao processo de ensino e aprendizagem da filosofia é atingido pela mesma dificuldade. Com isso tem-se em conta que esse tema se torna significativo cada vez que tratamos do acesso e da compreensão do saber filosófico; convém que se discutam os empenhos e preocupações relativas a métodos e procedimentos que o subestimem ou o substituam pela ideia de rigor relativo a teórico e prático no estudo de filosofia.

Palavras-chave: Saber filosófico. Saber "teórico"-"prático". Conhecimento.

Abstract: This current article consists of a reflection on the philosophical knowledge in face of philosophy systematization, that took place after its origins. Taking into consideration this fact as such, this article tries to make relevant, the debate that is able to recognize the philosophical content subjected to historical course of Philosophy. It is important to point out that it brings with itself peculiar difficulty in determining the main difference between Philosophy and other forms of knowledge. It is important to observe that the academic treatment given to the process of teaching and learning Philosophy, also faces the same difficulty. Having said that, this topic has become very meaningful every time we deal with comprehension and access to Philosophical knowledge; it is convenient that we discuss the effort and worries related to methods and proceedings that underestimate or replace it with the idea of rigor connected to theoretical and practical in the study of Philosophy.

Key-words: Philosophical Knowledge. "Theoretical" - "practical" Knowledge. Knowledge. 


\section{O saber filosófico para aquém de teórico e prático NASCIMENTO, Miguel A.}

Depois que a atividade de pensar ganhou sistematicidade desde a Antiguidade e adquiriu a designação de filosofia, passou-se a contar com suas definições fornecidas pelos filósofos. Como resultado disso conta-se hoje com a compreensão do saber filosófico dada pela própria história dessa atividade de pensar do homem. Mantém-se registrado através dela o conteúdo de filosófico vinculado ao pensar humano: seja aquilo que corresponde ao tempo mais recente, seja aquilo que corresponde a sua condição de outrora desde os tempos de Homero ou até mesmo de antes disso. Não obstante essa longa experiência com o filosofar, ainda permanece desafiador tentar identificar em que consiste este conteúdo de filosófico que perpassa a própria história da filosofia.

Sabe-se que o homem, ao se pensar como tal, põe-se simplesmente a filosofar, entendendo-se isso aqui no sentido de que sua própria natureza coincide com o "desejar conhecer" (ARISTÓTELES, 1987, [980a] p. 2). No caso, devemos dizer que o filosofar coincide com a experiência de conhecermos as coisas. Isso significa que chegamos a tratar do filosofar como tal porque algo em nós, a saber, o conhecimento, antes de qualquer outra coisa já está sempre em curso e ação. Apesar disso não se constata, por fim que, entre conhecer e filosofar seja suficiente definir um pelo outro - dizer o segundo pelo primeiro. Na relação entre um e outro, o saber filosófico não é alcançado nem se torna compreendido se meramente empregarmos o proceder comum com que os outros saberes definem uma coisa. Por isso acaba por se tornar desafiador compreender o conteúdo daquilo que se quer dizer por filosófico no próprio conhecimento filosófico. Mas, também, justamente por isso permanecemos sem poder abandonar a evidência de que o homem vive sob o modo da experiência de conhecer as coisas, devendo se exprimir inteiramente sob este modo mesmo. Assim, um tipo de saber implica o outro, mas não o substitui.

Este fato surge, pois, já como algo inerente à efetivação do pensar humano e se manifesta como questão no exercício do filosofar: logo que o poder de entendimento lógico e racional começa a operar, junto efetiva-se pelo pensar formato de mundo e de realidade, constituídos de dados e fatos; enquanto são pensados valem não por si mesmos, mas ao serem compreendidos, isto é, instituídos - criados. Esta efetivação do pensar, por causa disso, vira algo problemático. Quando então nos referimos ao acesso ao saber filosófico e a sua definição enquanto conhecimento, sua diferença específica em relação aos outros tipos de conhecimento apresenta-se estranhamente desafiadora. Entretanto, contrariamente ao que se possa admitir, o significado de desafio na compreensão deste saber diz respeito, propriamente, não a uma dificuldade de método relativa ao acesso e ensino-aprendizagem da filosofia; não se trata de um obstáculo externo a vencer para se chegar até ele, como pode aparentar querer dizer o termo "desafio". O que desafia é aquilo que nos chega com nossa percepção de que é em vão reduzirmos o conteúdo do saber filosófico a um conhecimento determinado, visando apenas sua efetivação exitosa, através da qual é possível compreender objetivamente tudo aquilo que se encontra manifesto e dizível. E que isso teria de ser assim, justamente para impedir no saber filosófico sua propensão a escapar dos critérios que a validez de um conhecimento determinado exige.

Em conseqüência, esta propensão passa a ser tachada de algo negativo e irreal, por ser apenas estranho, em vez de ser tomada como o elemento natural do saber filosófico. No decorrer da história da filosofia manifesta-se a necessidade de chamar atenção para o contrário disso; registra-se a percepção de que filosofar inclui, antes de qualquer coisa, justamente "a busca de tudo o que é estranho e problemático no existir" (NIETZSCHE, 1988, p. 258) A ênfase aqui resulta de que importa fazer residir o fundamental não nos dados e fatos, mas no tempo como o simples comprendê-los. 


\section{O saber filosófico para aquém de teórico e prático NASCIMENTO, Miguel A.}

Esta peculiar estranheza em suas diversas formas já surge, portanto, como aquilo que é o mais próprio do saber filosófico. Está, por isso, já na base do marco histórico em que vem a ser considerada para caracterização de primeiro filósofo e de começo do filosofar: Tales de Mileto (624-546/8 a. C), ao ser tomado tradicionalmente nesta posição de primeiro filósofo, é enaltecido por conseguir tornar exitoso compreender sob unidade o que percebemos enquanto a multiplicidade de coisas. Raciocínio e lógica são exercidos e fortalecidos, antecipando e possibilitando isso, mas não substituem, meramente com isso, o que está sendo aí pensado como elemento único capaz de atender ao "desejo" de tomar o diverso sob unicidade. Razão porque, neste caso, o "desejar conhecer" é reconhecido por Aristóteles como impulsionado pela admiração ("espanto") (ARISTÓTELES, 1987, [983a] p. 17), como se se tratasse de algo desconhecido e novo, mas na verdade é em face de tudo o que já está sempre sendo e em curso. Não quer dizer, então, que é para com o conhecer enquanto descoberta e comprovação de algo determinado. Por isso, também já para com o considerado primeiro filósofo, Aristóteles se ocupa de mostrar, como marco de partida enquanto máxima anterioridade, a condição do caráter peculiar do que é filosófico no conhecimento em relação à condição do caráter de físico no que diz respeito à natureza. Refere-se ao conteúdo do saber filosófico em Tales de Mileto fundamentado em algo não usual, no sentido de não visar a um ganho subsequente; fundamentado, então, em algo insólito e raro - por isso, difícil; difícil como é para o homem atingir a natureza de divino só com o saber que possui (Cf. ARISTÓTELES, 2011, 1141b2). Não se confunde, assim, com algo de cunho não pessoal, e sim - objetivamente falando - próprio a todo homem que filosofa. Por isso já constata isso igualmente também em outros casos - por exemplo, em Anaxágoras.

Muita ambivalência decorrente desta implicação do conhecimento filosófico com o conhecimento em suas outras formas permanece incorporada à sistematização que a filosofia alcançou em seu processo histórico. É exemplar neste sentido a concepção de conhecimento filosófico que ganha fluência sob a noção aristotélica de 'causa primeira' e 'primeiros princípios'. É exemplar, porque a propensão peculiar e de estranheza própria ao conteúdo de filosófico mantém sua valia vigendo na implicação entre um modo de ser do conhecimento e o outro entre o filosófico e o tipificado - em todo o percurso histórico da filosofia. Consequentemente, ela podia ter ganhado proeminência enquanto o elemento fundamental da diferenciação entre filosofia e outro conhecimento - como a ciência, especialmente. Não é, porém, o que ocorreu, embora sem poder impedir-se de se manter subjacente e subentendida. Mantém-se na condição de poder ser percebida e trazida à tentativa de ser mais bem compreendida e debatida em direção ao para aquém disso; mas muito mais também, na condição de ser confundida e substituída por modos de sua suplantação. A partir da idade moderna, a superestima por classificar e categorizar as ciências favorece isso. A propensão ao caráter enigmático de "estranhamento" é instada a encontrar resolução em faculdade calculativa e de representação.

O modo de proceder aristotélico favorece o entendimento que viemos a ter de "teórico", no que tem de semelhante ao modo de operar das ciências, que tomam por verdade a causa daquilo que vem a ser definido. Uma ciência pertencente à natureza de teorético (como a metafísica, a física e a matemática) possui tal critério para a verdade, diferenciando-se, com isso, daquelas ciências que tomam por verdade não o conteúdo de causa (o caso do saber prático e do saber poético). Em alusão a isso se pode perceber que o conteúdo de filosófico na metafísica (filosofia) possui interseção (o caráter de teorético) com as ciências (física e matemática) de mesma categoria, conforme se constituem. O teorético, na filosofia, põe o filosofar sob o mesmo modo teorético-especulativo de ciência como "conhecimento discursivo" que vale para a física e matemática. Por isso também, mesmo depois de Aristóteles, ele permanece na condição de poder ser considerado (compreendido) e conduzido (subordinado) pelo êxito do teórico efetivado 


\section{O saber filosófico para aquém de teórico e prático NASCIMENTO, Miguel A.}

conforme atuam as outras ciências (física e matemática) de mesma categoria - no caso, que consiste em constatar o que resulta definido. No decorrer da idade moderna, o vínculo que o termo "teórico" mantém com isso volta-se para conceitos como o de teoria do conhecimento e o de psicologia.

Essa base aristotélica permite configurar-se uma definição do saber filosófico, em que o elemento peculiar de filosófico preexiste no conhecimento teorético, sob o modo de comunhão da "inteligência com ciência" e ao tempo em que é "encabeçado pelo conhecimento das coisas mais valiosas" (ARISTÓTELES, 2011, 1141a 9-21). Em tal conjunção, o saber filosófico se mostra como um conhecimento mais "apurado" do que a ciência, uma vez que ultrapassa a condição de se consumar na mera dependência dos "princípios" - pressupostos; vai além dessa condição, própria à ciência ("conhecimento discursivo"), mas comungando com esta, ao atingir a verdade, para a qual convergem ambas as formas de saber.

Pode-se perceber aí uma articulação elaborada - uma moldura em que o saber filosófico pode se mostrar configurado, podendo ser notado graças à definição. Subsiste aí uma ambivalência no sentido de que o conhecimento filosófico é apresentado como a implicação entre duas valias de teor de saber. Devemos neste ponto examinar bem o fato de se poder mostrá-lo através de definição; de ele parecer valer pelo conjunto de elementos que compõem a definição de conhecimento filosófico na referida "comunhão" com outros saberes. Isso ocorre em sintonia com a gradação dos saberes, para que o saber filosófico possa ser percebido na posição de definido, graças à definição dos demais do conjunto do nivelamento hierárquico (Cf. PLATÃO, 2000, [510a-511e] p. 314-317; [533b-534b] p. 345-347). Trata-se de uma valia conseguida pela conjuntura e interesse de definição e, com isso então, projetada para o saber filosófico poder ser compreendido em sua outra valia - a da essência de "princípios" na instância do "inteligível". De modo analálogo, Aristóteles tem em consideração todo o amplo espectro do conhecimento, que se encontra implicado necessariamente nas atividades humanas. $O$ conhecimento assim se vincula a estas atividades como grau de excelência de nosso poder tratar das coisas, tanto as que se dão a perceber sob o modo teorético com que nos referirmos a elas, como as que se dão a perceber e ser referidas sob o modo do saber prático e do fazer técnico enquanto produção. Neste sentido, o saber filosófico enquanto conhecimento é apresentado também não de modo isolado disso, mas em comunhão com isso. O próprio Aristóteles, desse modo, apresenta o conhecimento filosófico implicado a outros saberes, a partir de que, em conseqüência, temos de buscar o acesso e o conteúdo de filosófico. Deve-se considerar bem que nesta validez, para o saber filosófico ser percebido enquanto definido, subjaz permanentemente a valia para a qual foi articulada a definição - a valia de origem como procedência. Outra coisa, diferente, é pensar o saber filosófico sem a conjuntura derivada do propósito de mostrá-lo definido em termos de se poder ter em vista a configuração da realidade como um ente; em razão da configuração, o poder de compreender e de estabelecer definições é submetido a comparações de dados e fatos entre si. Neste sentido de realidade configurada e de comparações encontra-se, então, permanentemente em aberto também a chance de que a relação entre o caráter de teorético e de prático seja confundida ou reinterpretada - no sentido de alterada. Assim, as dificuldades atuais relativas a isso, prendem-se ainda também a este fato da pretensão de um definido conhecimento filosófico.

Enquadrado em uma definição aprontada, ou seja, submetido a limites, para ser mostrado e apreendido como objeto, o saber filosófico deixa ocultado e apenas subentendido a natureza da verdade, concebida e implicada na complexidade do conteúdo originário relativo à "contemplação". Como foi referido acima, tem-se configurada a definição fornecida por 


\section{O saber filosófico para aquém de teórico e prático NASCIMENTO, Miguel A.}

Aristóteles, enquanto uma compreensão do conhecimento filosófico em que diz ser este saber certa "combinação" entre o "conhecimento científico e a inteligência".

Entende-se ter de haver o outro elemento da "combinação" - a intuição raciocinativa ("inteligência"). Ela leva a se perceber o que na natureza há de "extraordinário" e até "divino". Por isso, mesmo nos outros conhecimentos é este saber que está na base sob a forma de "excelência" enquanto implicação com a verdade dos "princípios":

[...] é preciso que o sábio não apenas conheça o que depende dos princípios, mas também acerte a verdade sobre os princípios. Conseqüentemente, a sabedoria é inteligência com ciência - como que uma ciência encabeçada pelo conhecimento das coisas mais valiosas" (ARISTÓTELES, 2011, 1141a 9-21).

Mas esta mesma concepção também é capaz de dar curso à valia que faz preponderar ser dissimulada e confundida. Razão de parecer suficiente achar que o filosofar resulte meramente no dizer em que consiste o próprio conhecer, como algo sintomático, ao tempo em que o conhecimento filosófico figuraria automaticamente como uma espécie de extensão e desenvolvimento do conhecimento demonstrativo como tal e respectivo processo evolutivo. Em consequência, isto faz com que nossa compreensão deste fato se alimente mais de certa digressão de cunho teórico em pról do conteúdo de filosófico enquanto conhecimento, do que da diferenciação e peculiaridade que este saber requer para ser compreendido. $O$ caráter de digressão induz à suficiência do conhecimento filosófico como saber que teria também de produzir definição com base em critério de fazer valer por verdadeiro, próprio às demais formas de conhecimento. Estabelece, para o saber filosófico, outra valia além da que lhe é intrínseca, embora não corrente.

A partir de se observar esta ambivalência de cunho desafiador, depreende-se, por um lado, a decorrência natural entre o que o homem é e sua atividade de filosofar: inclinação conforme o querer saber sobre tudo, sem que fizesse sentido impedi-lo disso em nada, nem também custasse manter isso e corresponder a ele como o que há de melhor. Mas, por se tratar de uma ambiguidade, depreende-se também, por outro lado que, para explicá-lo, teria de ganhar prioridade contar-se com a lógica da decorrência natural que há entre uma coisa e outra: o que se encontra dado e os infindáveis modos como consegue se manifestar. Ganha proeminência, na condição de algo óbvio, o que é o filosófico no homem, enquanto o que ele pode dizer como o próprio manifestar destes inumeráveis modos de manifestação. A percepção de se passar de grau mais inferior para grau mais elevado em complexidade de compreensão disso conseguiu alcançar a convicção de ser o elemento principal desta lógica. O próprio Aristóteles apresenta, enquanto exemplo disso, a experiência de conhecimento concernente ao médico que cura alguém em particular e que, em grau seguinte, então enquanto repetição correspondente, pode se estender a toda e qualquer pessoa que necessite de igual procedimento e efeito - não só a alguém em

\footnotetext{
${ }^{1} \mathrm{O}$ entendimento disso, porém, requer considerar que está sendo levado em conta disposições em nós que nos permitem chegar à verdade tanto relativamente às coisas variáveis como às invariáveis, através de formas de conhecimento (que são: o conhecimento científico, o de discernimento, a sabedoria filosófica, e a inteligência) (ARISTÓTELES, 1992, [1141 a] p. 118). Esta informação, ao mesmo tempo em que indica o que é a filosofia, não deixa, imediatamente claro aquilo mesmo que está na informação. Para se saber em que consiste a "combinação" entre o conhecimento científico e a inteligência, seria preciso saber também o que é cada um desses conhecimentos que possibilitam a "combinação". Portanto, requer procurar saber o que Aristóteles diz sobre o conhecimento científico e a inteligência - não é propósito mostrá-lo nesta oportunidade.
}

Trilhas Filosóficas, Caicó, ano 11, n. 2, Jul.-Dez. 2018, p. 11-22. 


\section{O saber filosófico para aquém de teórico e prático \\ NASCIMENTO, Miguel A.}

particular, a "Cálias" ou "Sócrates" (ARISTÓTELES, 1987, [981a5] p. 5). Por se tratar de abrangência da universalidade, este grau segundo pode ainda ser experimentado enquanto um terceiro grau e enquanto outros a seguir. Entretanto, a referência precípua a tais graus recai no fato de ser possível fazer coincidir, no "desejar conhecer", poder partir da experiência e poder chegar a uma instância última.

Pode-se dizer, nesse sentido, que concerne ao homem poder agir em vista daquilo que ele quer; poder conduzir a própria vontade pela ação que lhe convém. No entanto, não é isto que ganha este lugar diretamente e sob isenção. Em torno da categorização em teorético, praxis e poiesis estabeleceu-se a relação entre teórico e prático, que se antecipa permanentemente nesta posição. Prevalece como a garantia do rigor, que é possível de se extrair do potencial de positividade própria ao conhecimento como tal. Da parte do caráter de prático logo aparenta estar em jogo também uma necessidade de valor político-moral positivo, intrínseca ao nosso ser, conforme devamos agir a cada passo que damos. De modo que aquele princípio de liberdade, intrínseco ao "desejo" de conhecer, tem de competir com a chance, permanentemente em aberto, de que a relação entre teórico e prático o sobrepuje e predomine na condição de base de compreensão e explicação do conteúdo da filosofia.

Quando, depois disso, referimo-nos ao que devemos entender por saber filosófico e sua diferença específica entre outros tipos de conhecimento, deparamo-nos com o fato da efetivação disso. Entra em jogo a necessidade de eficácia e competência relativamente a compreender e exprimir isso. Em face disso, o acesso ao saber filosófico "aparenta" implicar capacitação e método para isso, a partir de tarefa prestabelecida. É certo que o acesso ao saber filosófico requer um tipo eficaz da aprendizagem de seu conteúdo. Mas o significado de "eficaz" aí precisa implicar aquele "desafio" de se conseguir atingir o conteúdo de filosófico, que desde sempre vige subjacente à efetiva sistematização histórica que a filosofia alcançou.

Deve-se perguntar agora: A dificuldade que se prende a isso não é peculiar à questão do filosofar como tal, como um desafio que lhe é inerente? Ou concerne antes à incapacidade de compreender o conhecimento como tal e, em conseqüência, não se comprende também o tipo de conhecimento que é o filosófico? Ou pode concernir a qualquer outra coisa que não seja o que diz a primeira pergunta, por considerá-la, no mínimo, insuficiente? A resposta afirmativa à primeira interrogação precisa ser priorizada. Por não ter sido prevalecente historicamente, a referida dificuldade passou a demandar eficácia e dispositivos tidos por adequados à compreensão disso.

Pode parecer que teríamos de remover certo impedimento circunstancial ou não, que estivesse a prejudicar nosso raciocínio e a atingir nosso entendimento a cerca do que poderia ser filosofia; que fosse, por isso, necessário recorrer a critérios e métodos de conhecimento, em lugar de retornar sempre mais uma vez à origem de filosófico na própria filosofia. É como se se tratasse de algo que não foi descoberto ainda, a exemplo daquilo que passa a ser compreendido a partir de uma lei que o determina ou rege. Entretanto, vale mais pensar a questão no que já foi descoberto, pois não se chegaria a tal grau de exigência na atualidade, caso não se contasse com o que já foi adiantado sobre isso pelos pensadores antepassados. Neste sentido, ao se fazer referência agora ao sentido de teórico, de um lado é já porque não se pode mais negar sua existência no decorrido conhecimento filosófico; de outro lado, é também porque se diferencia conforme designação de prático, no que este já possui disso como significado. Mesmo assim, embora o tratamento disso implique inteiramente o como foi tratado na Antiguidade, não tem sido o interesse por aquele começo o que se quis deixar prevalecer depois. Tal fato se poderia acusar, por exemplo, no emprego moderno-contemporâneo da noção de teórico e prático e conseqüente caracterização de Filosofia Teórica e Filosofia Prática. A distinção entre ambas

Trilhas Filosóficas, Caicó, ano 11, n. 2, Jul.-Dez. 2018, p. 11-22. 


\section{O saber filosófico para aquém de teórico e prático NASCIMENTO, Miguel A.}

deveria ocorrer no sentido de que o conteúdo originário da "contemplação" continue sendo o motivo único para derivação de toda experiência nova e tentativa de ultrapassá-lo, se vier a ser possível. Em vez disso, a relação entre uma e outra segue motivação diferente desta: inspira-se na relação teórico-prático já garantida pelo caráter de validação do conhecimento teórico-científico. Assim, não se torna secundária, no sentido de deixar que a motivação filosófica para investigar e compreender o teorético originário da "contemplação" venha a ganhar primazia e intensidade em toda reflexão filosófica.

Ao nos referirmos ao termo "teórico", pomo-nos na compreensão de elementos de constituição de princípio: constituem partida e base de se determinar com o entendimento relações de conexão, variação, continguidade, etc., no trato com as coisas. A palavra "teoria", de origem grega (theoria), nos chega sob a noção do ver contemplando e observando; o significado se mantém, estendendo-se a: examinar, verificar, estudar, etc. Avança-se no sentido de se chegar a comprovar fatos a partir princípios. O conhecimento filosófico evolui nesta compreensão, sobretudo como extensão relativa à filosofia antiga. Em conexão com isso encontram-se as discipinas que se consideram pertencentes à Filosofia Teórica (entre outras, a Teoria do Conhecimento) em contraste com as da Filosofia Prática (entre outras, a Filosofia Política). Se a palavra "teórico" induz a essa compreensão na disciplina Teoria do Conhecimento, é a mesma coisa o que passou a se dar com as demais do mesmo elenco, naquilo que há de comum entre elas: seria fundamentalmente o que "teoria" tem de assegurar como "princípios" no conhecimento; é, sobretudo: o que podemos conhecer - em que limites de abrangência de saber podemos assegurar conhecimento. Em outros termos, a partir da delimitação e extensão de nossa experiência de conhecer devemos distinguir elementos de constituição de conhecimento, incluindo a origem ou fonte e estrutura. Procura-se anular aí todo o desafio de estranheza submetendo-o à prova e comprovação, para argumento quanto ao que se pode ou não conhecer. Também assim são as condições para haver conhecimento: capacidade de uma estrutura de sujeito e objeto ou de uma consciência psicológica capaz de distinguir e apreender dados externos a si própria. Mas justamente na base de garantia de teórico, agora na unidade de princípios, sustenta e garante um movimento de vir para si tudo o que parece lançado em sua frente, no modo de representação desse todo. Trata-se de uma dinânica mediante relação entre o ente que percebe e o ente percebido, resultando em processo de representação enquanto conhecimento. Importa apenas a noção de "garantia de teórico", como a possibilitação deste processo de conhecimento: de um lado, porque indica dependência do conteúdo metafísico de princípios para base teórica - mas, como se fosse algo diferente de uma repetição do conteúdo de metafísico de desde a Antiguidade. Em razão disso aparece, por outro lado, a indicação de que a unidade da subjetividade no sujeito seria uma espécie de transferência engenhosa do conteúdo metafísico da "substância"; um intento capaz de satisfazer ao anseio da certeza e verdade afeito à modernidade, mas também ainda dependente da invariabilidade de teor divino, transferida para princípio de representação e base de conhecimento. Com o passar do tempo e o poder de ver mais claramente de que modo é enfim concebido, seu conteúdo nos princípios a justificarem o caráter de teórico vem a se mostrar não propriamente fundamentado. É o que pode afirmar aquele que se propuser a constatar que tal sujeito ou consciência consiste em uma 'crença' metafísica; consiste no que “creio que sou eu quem faz algo, que sofre algo, quem 'tem' algo, quem 'tem' uma propriedade" (NIETZSCHE, 2008, 2[83], p. 102). Resulta forçoso um conflito na necessidade de justificar o conteúdo da verdade garantido pela subjetividade do eu-consciência e pela proveniência da instancia divina. De modo análogo, mais adiante no tempo, o impasse ocorre vinculado às condições funcionais da consciência humana. É atribuída à consciência a operação de conhecimento do mundo, que lhe seria necessariamente externo. Neste caso resultará conflitante, de alguma forma, a justificação da qual depende a garantia de validade objetiva e de verdadeiro no 


\section{O saber filosófico para aquém de teórico e prático \\ NASCIMENTO, Miguel A.}

processo do conhecimento: uma vez que já se parte da consciência, para não depender de seus antecedentes metafísicos, a necessidade destes ou de sua exclusão na garantia da validade, põe sua justificação em conflito. Assim, pode alguém criticar a concepção de validez de um "mecanismo" em que "dados da consciência", considerados apreendidos por ela, mas também "exteriores" a ela: põe em dúvida se admitir "a validade de nossos conceitos, ainda que seja no campo da lógica, sobre a base da investigação psicológica de nossa consciência" (GADAMER, 1983, p. 90). No entanto encontra-se sob esta medida a possibilidade de vir a ser definido todo conhecimento (matemático, metafísico, teológico, conhecimento da natureza, da história, sociológico, antropológico, etc., e também o conhecimento filosófico). Seria a partir disso que se poderia dizer se existe um tipo entre todos eles que se possa considerar o mais fundamental de todos eles.

Combina com isso - com "a equiparação de todo conhecimento com o conhecimento científico" (GADAMER, 1983, p. 89) - ter-se recorrido depois a disciplinas como Teoria do Conhecimento, para se assegurar princípios de partida e acesso ao conteúdo da filosofia. E, além disso, sem se procurar mais compreendê-la junto ao sentido de teorético concebido por Aristóteles em relação à procedência filosófica; ou seja, sem buscar realcançar o conteúdo de teorético de origem enigmática na "contemplação" para, a partir daí ainda procurar tomar a direção do aquém disso. Assim, tudo o que já tinha sido estabelecido como conteúdo de filosófico pela Antiguidade, passa a ser compreendido pela estrutura de compreensão de uma validade objetiva fornecida pela relação sujeito-objeto, caracterizada pelo filosofar da Modernidade. No entanto, para teórico, categorias, princípios, etc., são utilizados os mesmos critérios antigos. Depois de se submeter o conteúdo de questão filosófica ao conteúdo do conhecimento, os critérios (origem, método, validez, etc.) para compreender e definir, inerentes à disciplina Teoria do Conhecimento, tornam-se a base de compreensão e definição também do conhecimento filosófico.

Mesmo suscitando mal-entendido, ainda assim passa a vigorar como base essencial para nortear o acesso ao conhecimento filosófico e processo de sua aprendizagem; serve de exigência de rigor para cobrança acadêmico-curricular relativa a eficácia e competência no ensino e estudo da filosofia. Está em jogo e debate envolvermo-nos com dificuldades em entender o conhecimento filosófico implicado a conteúdo de teoria e ciência, incluindo condições de comprovação. Em meio ao significado de teoria e sua relação com ciência - enquanto conhecimento, o cohecimento científico se interpõe e dá chance de se confudir esses conhecimentos. Torna-se freqüente não se conseguir superar a distinção entre conhecimento filosófico e conhecimento científico, como se o mais importante fosse uma diferenciação eficaz entre um e outro; como se o conhecimento filosófico não tivese de ser explicado primordialmente pelo realcance do conteúdo originário de "contemplação"; como se ele se caracterizasse por figurar na abrangência dos tipos de conhecimentos que são possíveis, conforme se entende isso e concebe a partir da Teoria do Conhecimento. Não surpreende, pois, se na rotina acadêmica ocorre de ser cobrado mais objetividade relativamente ao que se explica e conceitua em filosofia. Assim, para que o saber filosófico consiga também ser compreendido como conhecimento, é excluída sua particularidade de estranheza, a fim de vir a se pautar diretamente pela relação entre teoria e prática. Resulta, por causa disso, dizer-se separando Filosofia Teórica e Filosofia Prática, quando, na verdade isso inclui uma implicação recíprocoinseparável entre ambas: em certo sentido, uma quer dizer também a outra - o sentido em jogo aqui é a condição da filosofia de consistir em conhecimento e, para se manter assim vem a precisar, como qualquer outro tipo de conhecimento, de princípios fundamentais, a partir de que pode emitir objetivamente declarações, argumentos, explicações, etc; produzir definições, conceitos, etc.

Trilhas Filosóficas, Caicó, ano 11, n. 2, Jul.-Dez. 2018, p. 11-22. 


\section{O saber filosófico para aquém de teórico e prático NASCIMENTO, Miguel A.}

A questão em jogo é já antiga. Para indicar isso, recorro a um parêntese, em que a noção de teórico e de prático excede a definição dada. Isto quer dizer que essa questão possui em qualquer tempo o tipo de dificuldade que lhe é intrínseco, conforme o exemplo seguinte. Dentre argumentos empreendidos por Platão contra o pensamento dos sofistas - aqui, os de Protágoras -, um se refere a uma base teórica para conhecimento verdadeiro, sob a noção do princípio de que o "homem é a medida de todas as coisas"; outro se refere à noção de "justiça e bom senso", como um saber de cunho prático, acessível a qualquer pessoa. No primeiro caso trata-se de circunstância em que Sócrates, enquanto personagem interlocutor de uma conversação menciona Protágoras, no intuito de mostrar que precisamos avançar ao máximo em nossa compreensão do conhecimento. Teríamos de nos autosuperar, ultrapassando desde nossa percepção sensorial até o último grau de impedimento rumo à definição efetiva das coisas. Mas mesmo chegados aí, ainda não teríamos alcançado o alvo destinado. Por isso, ele empreende a tarefa de levar a questão ao seu nível mais elevado. O que interessa destacar aqui não é, propriamente a direção de submeter a questão ao seu esgotamento. Interessa antes, apontar para a motivação fundamental voltada para a origem do saber filosófico; voltada, portanto, para a complexidade de seu conteúdo concernente ao fato de que, desde sempre está em jogo precisarmos compreender o conhecimento como algo que temos de adquirir, visto que não nascemos plenos de sabedoria como um deus. É aí que precisa residir o propósito de uma definição do conhecimento como tal, que devemos aprender. Mas vem à tona também o entendimento de que não se começa a aprender a partir do nada de conhecimento. Se aprender é o mesmo que se tornar sábio naquilo que se aprende, então também deve coincidir conhecimento e sabedoria (PLATÃO, 2001, [145de] p. 40). Assim, parece ser já conhecimento o que desde sempre se possui quando se aprende a conhecer as coisas. Mas, justo por isso, será que não cabe tomar o conhecimento em nós como 'medida' da verdade necessária a todo conhecer? Em meio a isso surge a pergunta: o que é o conhecimento? A falta de resposta satisfatória deixa a alternativa de se fazer encontrar a explicação do conhecimento no próprio homem. Com base nisso encontra-se a concepção de Protágoras, tal como interpretada por Platão: Seria o homem 'a medida' de verdadeiro para o conhecimento e essência das coisas (PLATÃO, 2001, [152a] p. 49), no sentido de posição de princípio e critério para teórico, consequentemente. Enquanto isso, porém, já está sendo reconhecido pelo próprio Sócrates que o essencial desta questão se encontra num estágio bem mais complexo do que este; num grau em que o conhecimento não teria como já se mostrar independente e para além do próprio aprender a conhecer - enquanto a sabedoria. Por isso, a avaliação da concepção de Protágoras deve ser considerada mais como espelho de insuficiência para teórico, como no caso da modernidade, com a Teoria do Conhecimento. A contraposição de Sócrates expõe a contradição: Se se admite que o homem seja a medida da verdade, seja no que se refere 'ao que é, como ao que não é', quando alguém afirmar ser falso o que quer que eu afirme ser verdadeiro, não poderei contestá-lo, uma vez que tenho de considerá-lo, além de mim próprio, a mesma medida da verdade também (Cf. PLATÃO, 2001, [171b] p. 79).

No segundo caso trata-se de circunstância em que Protágoras pode argumentar afirmando que a todos e a qualquer um impõe-se a observância à justiça e ao bom senso. Está na base de sua afirmação também uma necessidade imprescindível que é a da sobrevivência do homem. Protágoras lança mão de interpretar o cenário de um mito em que todas as criaturas mortais tinham recebido do poder divino sua existência na terra. $O$ homem, que chegara a conseguir prover-se de tudo para o viver e vencera já praticamente todos os respectivos obstáculos, permanecia, porém subjugado por um deles, ironicamente intransponível: o viver mesmo entre as pessoas! Qualquer tentativa de viver em grupo culminava em intolerância mútua, extermínio e ameaça de extinção da raça humana. Zeus, enquanto o próprio poder divino, teria imposto sob 


\section{O saber filosófico para aquém de teórico e prático NASCIMENTO, Miguel A.}

pena de morte a obediência irrestrita à justiça e bom senso. É que a convivência se apresentou como a impossibilidade única da sobrevivência do homem.

O argumento da necessidade de justiça e bom senso aparenta ser razoável porque condiciona a viabilidade da existência do ente homem. Quem se arriscaria contestá-lo ou substituí-lo por outro mais plausível? No entanto, algo de óbvio aí o condena: não é na razão direta de causa e efeito que se alcança a verdade do que é próprio ao homem como pode se dar com o que é próprio aos demais entes. É o que Protágoras não chega a considerar, ainda que constate que a necessidade humana de justiça e bom senso implica sobreviver ou morrer. Deixase confundir pela conveniência de que é governando pelo conhecimento e não pelo contrário disso (a "cólera", os "prazeres", o "medo", etc.); deixa-se aparentar compreender que "a ciência e a sabedoria sejam o que há de mais elevado entre as coisas humanas" (PLATÃO, 2000a [352b-e] p. 108-109). Por isso, Sócrates, na posição da própria concepção de Platão, contrapõe-se a Protágoras; quer mostrar que a gênese da justiça não concerne ao que convém, ainda que em face da necessidade de sobrevivência. Seria preciso dizer qual é o saber que pode definir justiça e bom senso. Não se trataria de um saber possível de ser ensinado. Era preciso considerar que o homem, sendo mortal como todos os demais entes depende, ainda assim, de um saber específico que lhe assegure a autoconservação.

Considerando-se esta instrução de Platão, o que se põe em jogo é o enigma da origem e do poder de conhecimento próprio do homem. O conteúdo do significado disso é que diz do saber filosófico e que teria de estar também na base da compreensão e explicação da justiça, do bom senso e do deliberar sobre isso. Assim, o saber de ética teria esta mesma base filosófica, em vez de outra possível de saber político derivado. Não se trata do conteúdo lógico com que o saber político pode explicar e justificar os costumes, mas do teor enigmático do conteúdo da verdade no saber filosófico pressuposto.

Para fechar o parêntese retomo o fato de a noção de teórico e prático se encontrar vinculada ao modo de se criar elementos e dispor deles para estruturar as condições de sistematicidade de determinado conhecimento. Quando dizemos Filosofia Teórica, está em sua base aquele significado de princípios. Quando dizemos Filosofia Prática - por tratar do modo de aplicação de fins e técnica à derivação de objetos diferentes dos que trata a Filosofia Teórica -, ela possui igualmente as condições de dependência de "princípios". Assim também o é qualquer ciência e todo tipo de conhecimento: demanda as condições de pressupostos como princípios - (e a filosofia não se confunde com a ciência mesmo enquanto tem em comum esta condição). O emprego de teórico num conhecimento, então - relativo à categorização através dos respectivos pressupostos - não se confunde com a origem filosófica de teorético, que toma parte na complexidade do conteúdo de "primeiro" e "causa" relativos à condição de metafísico para "filosofia primeira" aristotélica; não é como se o conteúdo para verdade não tivesse de implicar sempre ainda aquele enigma do conteúdo de "contemplação". A relação de teórico e prático, que se torna comum a qualquer forma de conhecimento e à filosofia como conhecimento, não visa redefinir o conteúdo de filosófico aí subjacente; somente sempre forjado é que pode torná-lo redefinido pelos critérios estabelecidos pela Teoria do Conhecimento - então condizentes com condições de sua possibilidade (fonte, abrangência, método, etc.)

A relação de teórico com prático, enquanto diz de sua aplicação como mecanismo e método para se mostrar aquilo de que se fala, informa só sobre dispositivo - conjunto de dados ou fatos - para se fazer ver algo. Teria de concernir, porém ao para aquém disso; teria de consistir "neste fazer ver", naquele "mostrar" anterior aos fatos, para não ser apenas uma espécie de preparação para tal coisa. No que se enfatizam mais um elemento da relação em detrimento do outro - por exemplo, mais o teórico do que o prático ou o inverso disto - foge-se do âmbito da

Trilhas Filosóficas, Caicó, ano 11, n. 2, Jul.-Dez. 2018, p. 11-22. 


\section{O saber filosófico para aquém de teórico e prático}

NASCIMENTO, Miguel A.

compreensão que leva a se concluir por Filosofia Teórica em oposição à Filosofia Prática. A compreensão disso não teria de dizer respeito a "dispositivo", mas ao conteúdo, ainda não descompactado da "contemplação", subentendido na intenção de seu começo na Antiguidade. Por concernir ao compreender e não a fato histórico, permanece único e mesmo problema, e com o vigor de ser "difícil" agora como o era em seu começo.

\section{REFERÊNCIAS}

ARISTÓTELES. Ética a Nicômacos. Tradução de Mário da Gama Kury. Brasília: Editora Universidade de Brasília, 1992, $3^{\text {a }}$ ed.

ARISTÓTELES. Ética a Nicômaco (Livro VI). Tradução de Lucas Angioni [Dissertatio, UNICAMP/CNPq, 2011] Disponível em: http://unicamp.academia.edu/LucasAngioni>. Acesso em: 21 fev. 2016.

. Metafísica. Edição em grego-latim-espanhol, por Valentin Garcia Yebra. Madrid: Editorial Gredos, 1987.

GADAMER, Hans-Georg. "Filosofia ou teoria da ciência?". In: A razão na época da ciência. Tradução de Ângela Dias. Rio de Janeiro, RJ: Edições Tempo Brasileiro, 1983, p. 88105.

NIETZSCHE, Friedrich. Sämtliche Werke. Kritische Studienausgabe (KSA), vol. 6. Edição de Giorgio Colli e M. Montinari. Berlin/N. York, dtv/de Gruyter, 1988.

Sämtliche Werke. Kritische Studienausgabe (KSA), vol. 12. Edição de Giorgio

Colli e M. Montinari. Berlin/N. York, dtv/de Gruyter, 2008.

PLATÃO. A república. Tradução de Carlos Alberto Nunes. Belém: EDUFPA, 2000. $3^{\text {a }}$ ed. Protágoras. Tradução de Carlos Alberto Nunes. Belém: EDUFPA, 2000a. $3^{\mathrm{a}}$ ed. Teeteto. Tradução de Carlos Alberto Nunes. Belém: EDUFPA, 2001. $3^{\mathrm{a}}$ ed. 